\title{
Lysyl oxidase modulates the osteoblast differentiation of primary mouse calvaria cells
}

\author{
ANJALI SHARMA-BHANDARI ${ }^{1}$, SUN-HYANG PARK ${ }^{1}$, JU-YOUNG KIM ${ }^{2}$, JAEMIN OH ${ }^{2}$ and YOUNGHO KIM ${ }^{1}$ \\ Departments of ${ }^{1}$ Biochemistry and ${ }^{2}$ Anatomy, School of Medicine, Institute of Wonkwang Medical Science, \\ Wonkwang University, Iksan, Jeollabuk-do 570-749, Republic of Korea
}

Received April 23, 2015; Accepted October 14, 2015

DOI: 10.3892/ijmm.2015.2384

\begin{abstract}
Lysyl oxidase (LOX) is an extracellular amine oxidase that mediates the formation of collagen fibers. Thus far, five $L O X$ family genes [ $L O X$, lysyl oxidase-like $(L O X L) 1$, LOXL2, LOXL3 and LOXL4] have been identified in humans, each encoding the characteristic C-terminal domains that are required for amine oxidase activity. During osteoblastogenesis, collagen fibers function as a three-dimensional scaffold for organizing mineral deposition. In this study, to assess the functional roles of the LOX family members in osteoblastogenesis, we investigated the temporal expression of these genes as a function of phenotypic development during the osteoblast differentiation of primary cultured mouse calvaria cells. Of the $L O X$ family members, only $L O X$ was prominently expressed during osteoblast differentiation. $L O X$ expression was highest on day 9 of differentiation, as shown by RT-PCR and western blot analysis. The expression pattern of collagen, type I, alpha 2 (COL1A2), which encodes the $\alpha 2$-chain of mouse collagen type I, was similar to that of $L O X$. The total amine oxidase activity of the differentiating calvaria cells exhibited a temporal pattern that paralleled $L O X$ expression, reaching the highest level on day 9 of differentiation. We also noted that the inhibition of the amine oxidase activity of LOX significantly suppressed both mineral nodule formation and the expression of osteoblast marker genes during the differentiation of primary calvaria cells Taken together, these findings suggest that the LOX-mediated organization of collagen fibers in the extracellular matrix is an important regulator of osteoblastogenesis.
\end{abstract}

\section{Introduction}

The extracellular matrix is thought to play a pivotal role in osteoblast differentiation. Fibrillar collagen type I in the extracellular

Correspondence to: Dr Youngho Kim, Department of Biochemistry, School of Medicine, Institute of Wonkwang Medical Science, Wonkwang University, Sinyong-Dong 344-2, Iksan, Jeollabuk-do 570-749, Republic of Korea

E-mail: youngkim@wonkwang.ac.kr

Key words: osteoblast, lysyl oxidase, differentiation, amine oxidase, collagen matrix functions as a three-dimensional scaffold for organizing mineral deposition in bone (1). Many studies have reported that altered cross-linking of collagen type I exerts significant effects on the differentiation and mineralization of various cell types, including endometrial cells, smooth muscle cells and mammary cells (2-4). The aberrant cross-linking of collagen fibrils has been observed in a number of bone disorders, including osteoporosis, osteopetrosis and diabetes-related bone disease (5-7). Lysyl oxidase (LOX) is a secreted, copper-dependent amine oxidase that plays a key role in maintaining the integrity of connective tissue by modulating the cross-linking of collagen monomers into insoluble fibers in the extracellular matrix. LOX oxidatively deaminates the $\varepsilon$-amino groups of peptidyl lysines into aldehyde groups in collagen; the resulting aldehydes spontaneously condense with unreacted $\varepsilon$-amino groups or neighboring aldehyde groups, resulting in the intra- and intermolecular cross-linkages found in insoluble collagen fibers (8).

Four LOX-like genes [lysyl oxidase-like $(L O X L) 1, L O X L 2$, LOXL3 and LOXL4)] have been identified in humans on the basis of their sequence similarity to $\operatorname{LOX}(9-12)$. We have previously demonstrated that each of the LOX-like proteins functions as an amine oxidase (13-16); however, the functional differences between these LOX family proteins have not yet been fully elucidated. Given the functional role of LOX in the formation of collagen fibers, it seems plausible that LOX and its paralogs may play a critical role in osteoblast differentiation. In this study, to explore the functional roles of LOX and its paralogs in osteoblastogenesis, we examined the temporal expression profiles of the $L O X$ family genes at both the mRNA and protein level as a function of phenotypic development during osteoblast differentiation. We assessed amine oxidase activity, the expression of osteoblast marker genes and mineral nodule formation in the presence and absence of beta-aminopropionitrile (BAPN), an irreversible inhibitor of LOX, during the differentiation of primary mouse calvaria cells.

\section{Materials and methods}

Primary osteoblast cell culture. This study was approved by the Ethics Committee of Wonkwang University following the guidelines for the experimental use of animals. Twelve newborn ICR mice (1 day of age) were purchased from Damul Science (Jungeub, Korea). The newborn mice were anesthetized and sacrificed with $70 \%$ ethanol. The calvaria of the newborn 
mice were dissected, and the bones were digested 5 times with $0.1 \%$ collagenase (Wako, Osaka, Japan) and $0.2 \%$ dispase (Roche, Basel, Switzerland). The cells isolated in the last 3 digestions were combined and cultured in $\alpha$-minimum essential medium ( $\alpha$-MEM) containing 10\% FBS, $100 \mathrm{U} / \mathrm{ml}$ penicillin and $100 \mu \mathrm{g} / \mathrm{m} 1$ streptomycin (Gibco-BRL, Grand Island, NY, USA). The primary osteoblasts were plated at a density of $1 \times 10^{5}$ cells/6-well plates in the presence of $50 \mu \mathrm{g} / \mathrm{ml}$ ascorbic acid and $10 \mathrm{mM} \beta$-glycerol phosphate (Sigma-Aldrich, St. Louis, $\mathrm{MO}, \mathrm{USA}$ ), and the culture medium was replaced every 3 days.

Reverse transcription-polymerase chain reaction (RT-PCR). Total RNA was extracted from the cultured mouse calvaria cells every three days, using TRIzol reagent (Invitrogen, Carlsbad, CA, USA), according to the manufacturer's instructions. One microgram of total RNA was reverse transcribed using $M-M L V$ reverse transcriptase (Promega, Madison, WI, USA) and random primers (Invitrogen), according to the manufacturer's instructions. For RT-PCR analysis, Ex Taq polymerase (Takara, Shiga, Japan) was used with primers specific to the $L O X$ family genes and collagen, type I, alpha 2 (COL1A2). The primer sequences used for RT-PCR are available upon request. The thermal cycling parameters were as follows: $25-30$ cycles at $94^{\circ} \mathrm{C}$ for $30 \mathrm{sec}$, $55-60^{\circ} \mathrm{C}$ for $30 \mathrm{sec}$, and $72^{\circ} \mathrm{C}$ for $30 \mathrm{sec}$, with a pre-denaturation cycle at $94^{\circ} \mathrm{C}$ for $4 \mathrm{~min}$, and a final extension at $72^{\circ} \mathrm{C}$ for $7 \mathrm{~min}$. The amplified PCR products were analyzed by electrophoresis on $2 \%$ agarose gels. Glyceraldehyde 3-phosphate dehydrogenase $(G A P D H)$ was used as an internal control. All RT-PCR analyses were performed in the linear range of amplification.

Quantitative PCR ( $q P C R)$. Total cDNA from the cultured mouse calvaria cells was prepared every 3 days as described above. For qPCR, a total volume of $10 \mu \mathrm{l}$, which contained $5 \mu \mathrm{l}$ of SYBR select master mix (Applied Biosystems, Foster City, CA, USA), $1 \mu \mathrm{l}$ of the total cDNA, and 10 pmoles of primers, was amplified using the StepOnePlus instrument (Thermo Scientific, Waltham, MA, USA). The thermal parameters involved an initial step at $95^{\circ} \mathrm{C}$ for $10 \mathrm{~min}$, followed by 40 cycles of $15 \mathrm{sec}$ at $95^{\circ} \mathrm{C}$, and then $60 \mathrm{sec}$ at $60^{\circ} \mathrm{C}$. The primer sequences used for qPCR are presented in Table I. The analyses were performed in triplicate for 3 independent experiments. Relative expression levels were obtained using the $\Delta \Delta \mathrm{Ct}$ method, as previously described (17). $G A P D H$ was used as an internal control, and the fold changes were calculated using the values of day 0 as a calibrator. Data from 3 independent experiments are presented as the means \pm SD.

Western blot analysis. This study was approved by the Ethics Committee of Wonkwang University following the guidelines for the experimental use of animals. Two rabbits (15 weeks of age; Damul Science) were used for the generation of a polyclonal antibody to LOX. After obtaining the polyclonal antibodies, the animals were anesthetized by an intramuscular injection of xylazine $(10 \mathrm{mg} / \mathrm{kg})$ and ketamine $(50 \mathrm{mg} / \mathrm{kg})$. After confirming that the hearts had stopped, the animals were sacrificed according to the guidelines. A recombinant form of the human LOX protein was expressed and purified as previously reported (13), and a polyclonal antibody to LOX was generated by immunizing rabbits with the LOX protein. Rabbits were injected intramuscularly with $300-400 \mu \mathrm{g}$ of the purified protein in a buffer containing $6 \mathrm{M}$ urea, $250 \mathrm{mM}$ imidazol and
Table I. Primer sequences used for qPCR analysis.

\begin{tabular}{|c|c|c|}
\hline Gene & Primer sequences & $\begin{array}{c}\text { Annealing } \\
\text { temperature } \\
\left({ }^{\circ} \mathrm{C}\right)\end{array}$ \\
\hline \multirow[t]{2}{*}{ GAPDH } & F: 5'-TGTCCGTCGTGGATCTGAC-3' & 59 \\
\hline & R: 5'-CCTGCTTCACCACCTTCTTG-3' & 59 \\
\hline \multirow[t]{2}{*}{ COL1A2 } & F: 5'-TGTGTTCCCTACTCAGCCGTCT-3' & 62 \\
\hline & R: 5'-CATCGGTCATGCTCTCTCCAA-3' & 60 \\
\hline \multirow[t]{2}{*}{$L O X$} & F: 5'-AAGCAGAGCCTTCCTGCAAA-3' & 57 \\
\hline & R: 5'-GGTCACAGCGGTCTCGTTGT-3' & 61 \\
\hline \multirow[t]{2}{*}{$L O X L 1$} & F: 5'-GGCCTCAGGGAGTGAACATG-3' & 61 \\
\hline & R: 5'-AAGACAGGGTCTGGCATCCA-3' & 59 \\
\hline \multirow[t]{2}{*}{$L O X L 2$} & F: 5'-CCTCCCTCCCGCTTTCA-3' & 58 \\
\hline & R: 5'-CAAGTGTGCAGTCCTGGGTTT-3' & 60 \\
\hline \multirow[t]{2}{*}{$L O X L 3$} & F: 5'-CCCCAGCAACAGACAGAACA-3' & 59 \\
\hline & R: 5'-GAGCTGCTGCCATCCTGTGT-3' & 61 \\
\hline \multirow[t]{2}{*}{ LOXLA } & F: 5'-GCAGCTTCCACTGCACTACACT-3' & 62 \\
\hline & R: 5'-TGTTCCGAGCGTCATCCA-3' & 56 \\
\hline \multirow[t]{2}{*}{$A L P$} & F: 5'-AACCCAGACACAAGCATTCC-3' & 57 \\
\hline & R: 5'-GCCTTTGAGGTTTTTGGTCA-3' & 55 \\
\hline \multirow[t]{2}{*}{$B S P$} & F: 5'-CCGGCCACGCTACTTTCTT-3' & 58 \\
\hline & R: 5'-TGGACTGGAAACCGTTTCAGA-3' & 58 \\
\hline \multirow[t]{2}{*}{ OCN } & F: 5'-CTCACAGATGCCAAGCCCA-3' & 59 \\
\hline & R: 5'-CCAAGGTAGCGCCGGAGTCT-3' & 63 \\
\hline \multirow[t]{2}{*}{$O P N$} & F: 5'-TCTGATGAGACCGTCACTGC-3' & 59 \\
\hline & R: 5'-CCTCAGTCCATAAGCCAAGC-3' & 59 \\
\hline \multirow[t]{2}{*}{$R U N X 2$} & F: 5'-AAATGCCTCCGCTGTTATGAA-3' & 56 \\
\hline & R: 5'-GCTCCGGCCCACAAATCT-3' & 58 \\
\hline
\end{tabular}

GAPDH, glyceraldehyde 3-phosphate dehydrogenase; COL1A2, collagen, type I, alpha 2; $L O X$, lysyl oxidase; $L O X L 1$, lysyl oxidaselike 1; $A L P$, alkaline phosphatase; $B S P$, bone sialoprotein; $O C N$, osteocalcin; $O P N$, osteopontin; RUNX2, runt-related transcription factor 2 .

$10 \mathrm{mM} \mathrm{K}_{2} \mathrm{HPO}_{4}$ on days 0,14 and 21. After the final injection, the rabbits were bled on days 7 and 14, and the antibodies were then tested using an enzyme-linked immunosorbent assay (ELISA). Antibodies were purified using a Protein A Agarose kit (KPL, Gaithersburg, MD, USA) according to the manufacturer's instructions. Culture medium from the mouse calvaria cell cultures was collected and concentrated 10-fold using an Amicon $10 \mathrm{kDa}$ cut-off filter (EMD Millipore, Billerica, MA, USA). Following concentration, samples of equivalent protein concentrations were subjected to sodium dodecyl sulfate-polyacrylamide gel electrophoresis (SDS-PAGE) on a $12 \%$ polyacrylamide gel and electrophoretically transferred onto a PVDF membrane (EMD Millipore). The membrane was blocked with 5\% skim milk in Tris-buffered saline with Tween-20 (TBST) for $2 \mathrm{~h}$ at room temperature, and was then incubated with a 1:1,000 dilution of the anti-LOX polyclonal antibody in TBST overnight at $4^{\circ} \mathrm{C}$. The membrane was washed with TBST and incubated with horseradish peroxidase-conjugated goat anti-rabbit immunoglobulin secondary antibody (\#G21234; 
A

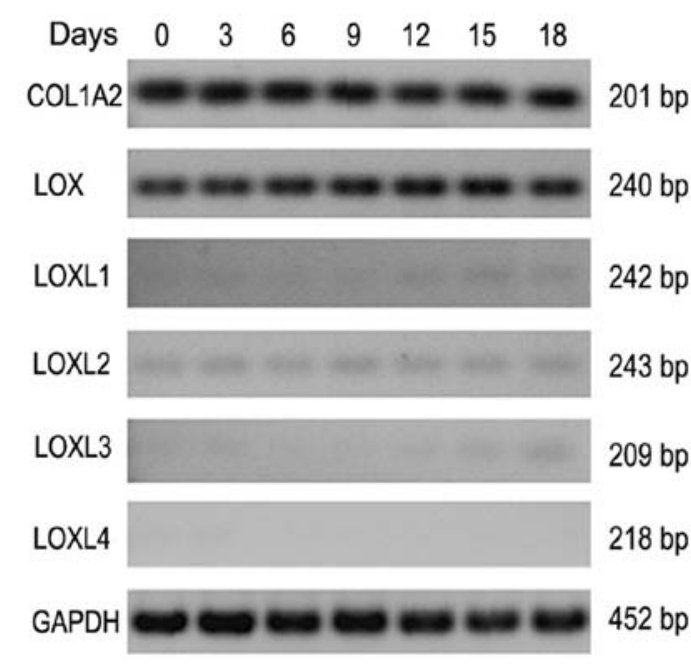

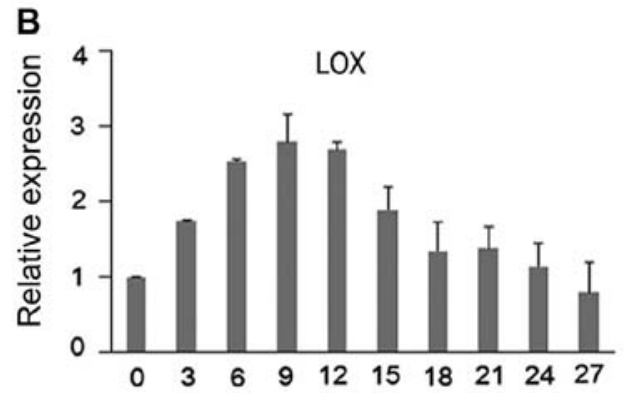

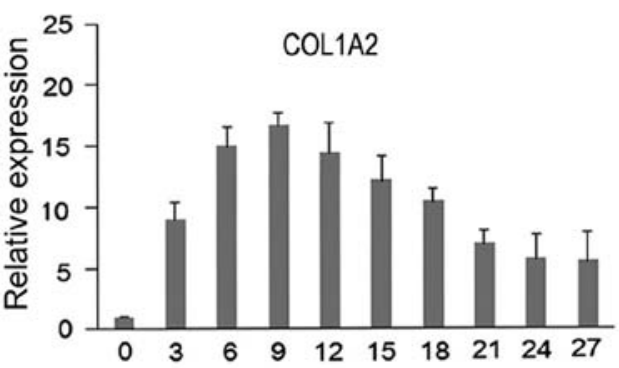

Figure 1. Expression of the lysyl oxidase ( $L O X)$ family genes and collagen, type I, alpha 2 (COL1A2). (A) A typical example of RT-PCR analysis using total RNA. The analysis was performed in triplicate, and all analyses produced similar expression patterns. GAPDH was used as an internal control. The sizes of PCR amplicons are indicated to the right of each panel. (B) qPCR results for quantitative analysis of LOX and COL1A2 expression. The mRNA expression relative to $G A P D H$ was determined and the fold changes were calculated using the values of day 0 as a calibrator. The assays were performed in triplicate, and the average is shown with an error bar representing the standard deviation. LOXL, lysyl oxidase-like.

Invitrogen) for $2 \mathrm{~h}$ at room temperature. The membrane was developed using the ECL Prime Western Blot Detection kit (GE Healthcare UK Ltd., Buckinghamshire, UK), according to the manufacturer's instructions. For quantitative analysis, data from 3 independent experiments were analyzed using Quantity One software (Bio-Rad Laboratories, Hercules, CA, $\mathrm{USA}$ ) and presented as the means $\pm \mathrm{SD}$.

Amine oxidase assays. The total amine oxidase activity of the mouse calvaria cells was assessed using a peroxidasecoupled fluorometric assay, as previously described (18). Following concentration using an Amicon $10 \mathrm{kDa}$ cut-off filter (EMD Millipore), the cell medium was pre-incubated, with or without $1 \mathrm{mM} \mathrm{BAPN}$, for $1 \mathrm{~h}$ at $37^{\circ} \mathrm{C}$ in the presence of $1.2 \mathrm{M}$ urea and $50 \mathrm{mM}$ sodium borate, $\mathrm{pH}$ 8.2. The cell medium was further incubated with $20 \mathrm{nM}$ calf skin collagen type I (SigmaAldrich) for $2 \mathrm{~h}$ at $37^{\circ} \mathrm{C}$. Fluorescence was measured using the SpectraMax M3 microplate reader (Molecular Devices, Sunnyvale, CA, USA) with excitation and emission set at 500 and $650 \mathrm{~nm}$, respectively. Data from 3 independent experiments are presented as the means $\pm \mathrm{SD}$.

Alizarin red $S$ (ARS) assay. Primary osteoblasts were plated at a density of $2 \times 10^{4}$ cells $/ 48$ wells in the presence of $50 \mu \mathrm{g} / \mathrm{ml}$ ascorbic acid and $10 \mathrm{mM} \beta$-glycerol phosphate (Sigma-Aldrich). BAPN (0, 1 or $2 \mathrm{mM}$ ) was added to the culture medium, and the medium was replaced every 3 days. For Alizarin redARS staining, cultured cells were fixed in $3.7 \%$ formalin and stained for 10 min with 2\% ARS (Sigma-Aldrich), pH 4.2. After repeated washing with distilled water, the bound ARS was dissolved in $10 \%$ cetylpyridinium chloride monohydrate, pH 7.0 (Sigma-Aldrich). The absorbance was measured at $545 \mathrm{~nm}$ using a microplate reader, and data from 3 independent experiments are presented as the means \pm SD.
Statistical analysis. Statistical analyses were performed by one-way ANOVA, followed by a multiple-comparison Tukey's test, using SPSS 12.0 software. P-values $<0.05$ were considered to indicate statistically significant differences.

\section{Results}

Expression of LOX family genes during osteoblast differentiation. To investigate the temporal expression of the $L O X$ family genes during osteoblast differentiation, we induced the differentiation of primary cultured mouse calvaria cells in the presence of ascorbic acid and $\beta$-glycerol phosphate, as previously described (19). qPCR analysis of several well-known marker genes associated with osteoblast differentiation, such as the genes encoding alkaline phosphatase (ALP), osteopontin (OPN), bone sialoprotein (BSP), osteocalcin (OCN) and runt-related transcription factor 2 (RUNX2), confirmed that osteoblast differentiation occurred in the primary mouse calvaria cells that we used (data not shown). For expression analysis of the $L O X$ family genes at the mRNA level, total RNA was isolated every 3 days, and RT-PCR analysis was performed using primers derived from the non-conserved 3'-UTR regions of the $L O X$ family genes. Throughout the differentiation period of the primary calvaria cells, only $L O X$ was predominantly expressed, whereas the expression of the other $L O X$ family genes was barely detectable (Fig. 1A). For quantitative analysis, qPCR was performed on the $L O X$ family genes. The expression of $L O X$ increased until day 9 of differentiation and then gradually diminished during the later stages of differentiation (Fig. 1B). The expression of the other $L O X$ family genes was undetectable throughout the differentiation period. COL1A2, which encodes the $\alpha 2$-chain of mouse collagen type I, produced an expression pattern similar to that of $L O X$; its expression increased until day 9 , and then gradually diminished thereafter (Fig. 1). 


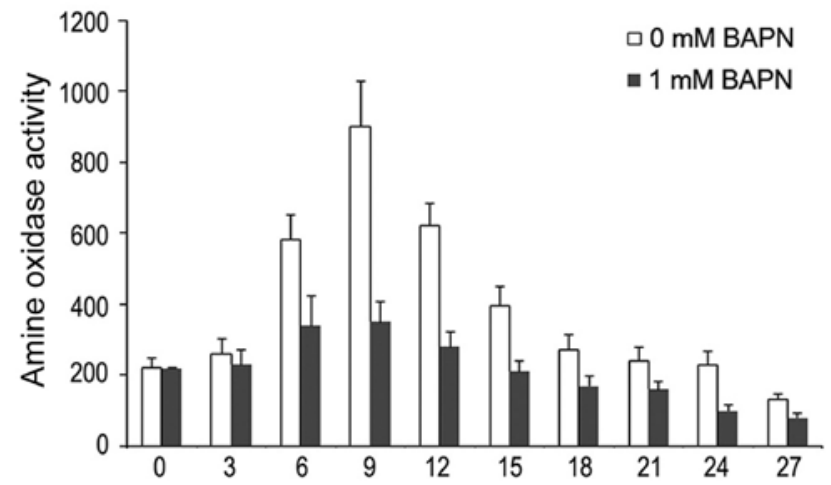

Figure 2. Total amine oxidase activity in the presence and absence of beta-aminopropionitrile (BAPN). Relative amine oxidase activity was expressed as fluorescence intensity. The assays were performed in triplicate, and the average is shown with an error bar representing the standard deviation.

Amine oxidase activity of primary calvaria cells during osteoblast differentiation. We assessed the total amine oxidase activity of the differentiating primary calvaria cells using the media of cultured cells, in the presence and absence of BAPN, which is a well-known specific inhibitor of LOX-derived amine oxidase activity. Total amine oxidase activity was evaluated using collagen type I as a substrate. We noted that total amine oxidase activity increased until day 9 of differentiation, and then gradually decreased thereafter (Fig. 2). Moreover, total amine oxidase activity was inhibited by treatment with $1 \mathrm{mM}$ BAPN compared to the background level for all samples tested (Fig. 2). The temporal pattern of total amine oxidase activity during osteoblast differentiation closely resembled the mRNA expression pattern observed for $L O X$.

Expression of LOX protein during osteoblast differentiation. To evaluate LOX expression at the protein level, we performed western blot analyses of the culture media collected throughout the osteoblast differentiation period. The culture medium was collected every 3 days, concentrated 10-fold, and then subjected to western blot analysis with an antibody specific to LOX. Analogous to the total amine oxidase activity, the highest expression level of LOX protein was detected on day 9 of differentiation, and then decreased thereafter, reaching the basal level (Fig. 3). These results suggest that the total amine oxidase activity of the differentiating mouse calvaria cells was derived from LOX protein, which was expressed and secreted into the culture medium.

Inhibition of the amine oxidase activity of LOX prevents osteoblast differentiation. To investigate the effects of LOX on the osteoblast differentiation of primary mouse calvaria cells, we inhibited the amine oxidase activity of LOX by including BAPN in the culture medium. We then assessed the effects of BAPN on mineral nodule formation, as well as its effects on the expression of osteoblast marker genes, namely $A L P$, $O P N, B S P, O C N$ and $R U N X 2$. We noted that BAPN substantially reduced the expression of all the marker genes tested in a dose-dependent manner (Fig. 4). Moreover, ARS staining suggested that the inhibitory effect of BAPN on mineral nodule formation was not evident during the early stages of differentiation (days $0-12$ ), but became distinct on day 15 , and

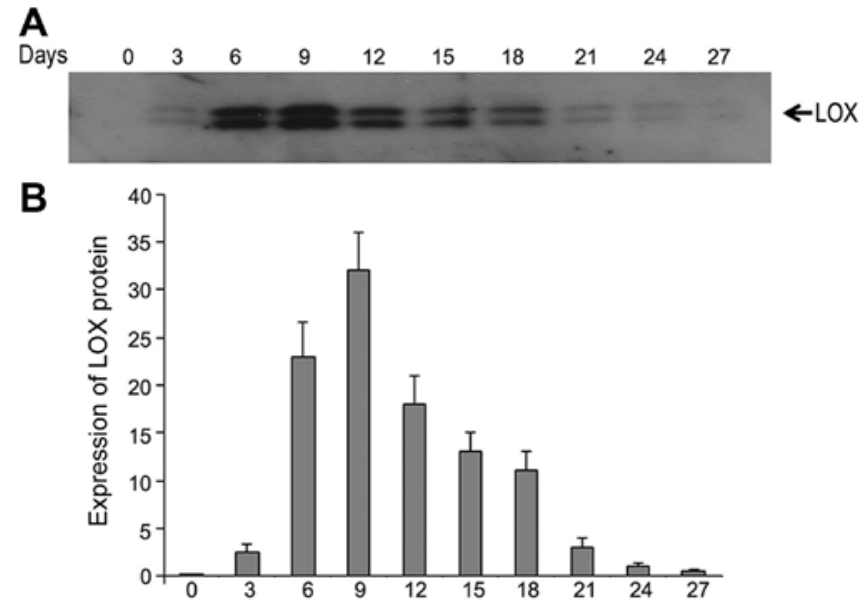

Figure 3. Western blot analysis of lysyl oxidase (LOX) protein expression. (A) A typical example of western blot analysis of concentrated culture media. The analysis was repeated in triplicate, and all analyses produced similar expression patterns. (B) For quantitative analysis, the densitometric intensity of the 32-kDa bands corresponding to LOX was determined, and the fold changes were calculated using the value of day 0 as a calibrator. The assays were performed in triplicate, and the average is shown with an error bar representing the standard deviation.

even clearer during the later stages of osteoblast differentiation (Fig. 5).

\section{Discussion}

Previous research has indicated that the human $L O X$ family genes, apart from LOXL2, are expressed in MC3T3-E1 cells, an osteoblastic cell line isolated from the calvaria of a latestage mouse embryo, during cell differentiation and matrix mineralization (20). The expression patterns of the $L O X$ family genes were shown to be distinct from one another in the MC3T3-E1 cells, suggesting that the formation of collagen fibers in osteoblast differentiation is regulated by the coordinated expression of $L O X$ family genes (20). However, in the present study, using primary cultured mouse calvaria cells, we found that, of the LOX family genes, only $L O X$ was predominantly expressed, and the expression of the other $L O X$ family genes was barely detectable. Additionally, collagen type I, the principal constituent of the organic matrix of bones, produced an expression pattern similar to $L O X$. The total amine oxidase activity of the primary calvaria cells paralleled the LOX protein levels in the culture medium, indicating that the amine oxidase activity of the primary calvaria cells originated from the LOX protein secreted into the culture medium. The inhibition of the amine oxidase activity of LOX using BAPN, an irreversible inhibitor of LOX, significantly suppressed both mineral nodule formation and the expression of osteoblast marker genes during osteoblast differentiation of the primary calvaria cells, thus suggesting that LOX plays an essential role in regulating osteoblast differentiation through the amine oxidase activity required for the formation of collagen fibers. BAPN, a specific inhibitor of the amine oxidase activity of LOX, has previously been reported to induce the accumulation of abnormal collagen fibrils in osteoblastic MC3T3-E1 cells (21), further supporting our findings that LOX, but not the other LOX family members, is responsible for the amine 

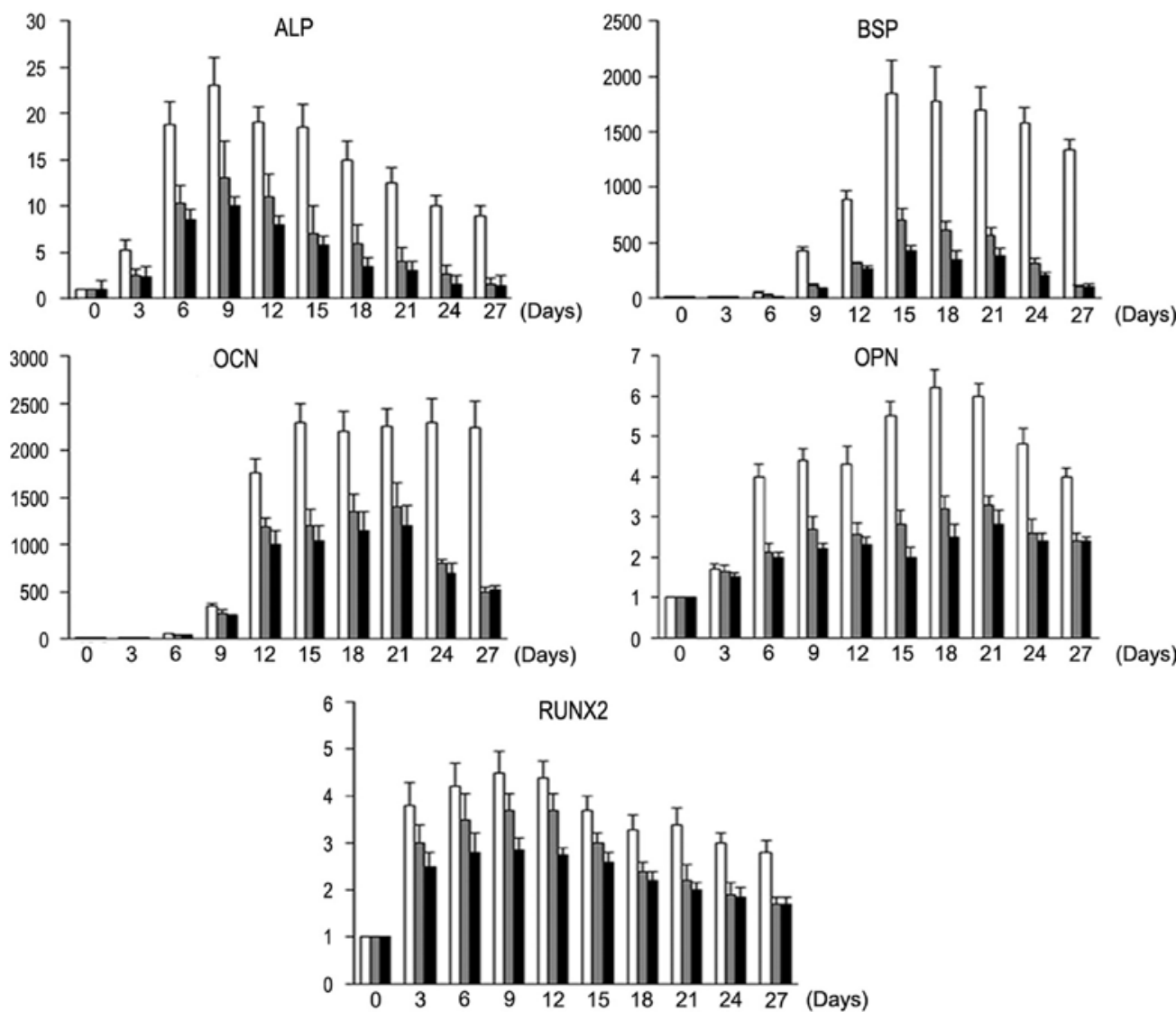

Figure 4. Expression of osteoblast marker genes in the presence and absence of beta-aminopropionitrile (BAPN). The mouse calvaria cells were cultured in the presence of 0,1 or $2 \mathrm{mM}$ BAPN. The white bars indicate assays with total RNA from the cells cultured with $0 \mathrm{mM}$ BAPN, the gray bars with $1 \mathrm{mM}$ BAPN, and the black bars with $2 \mathrm{mM}$ BAPN. The mRNA expression relative to GAPDH was determined, and the fold changes were calculated using the values of day 0 as a calibrator. The assays were performed in triplicate, and the average is shown with an error bar representing the standard deviation. ALP, alkaline phosphatase; OCN, osteocalcin; OPN, osteopontin; BSP, bone sialoprotein; RUNX2, runt-related transcription factor 2.
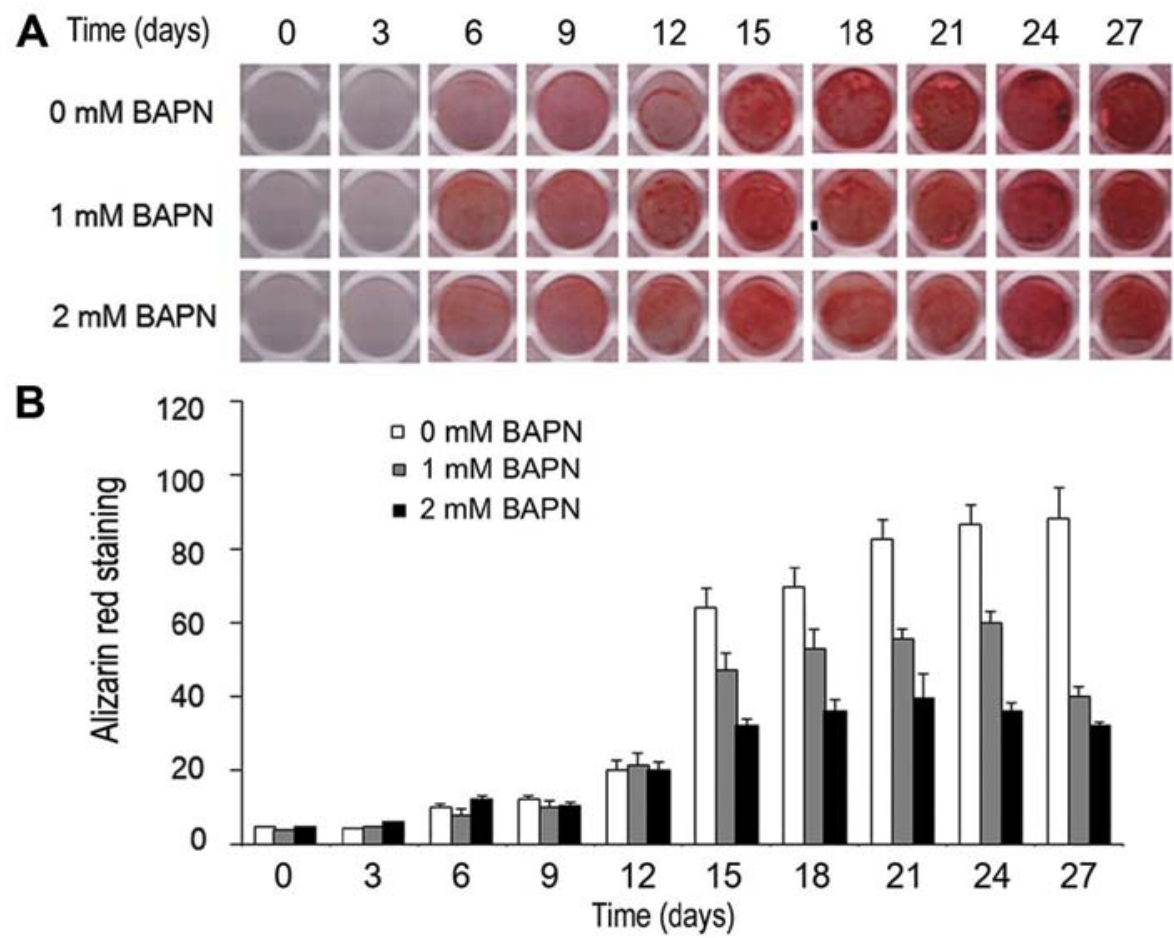

Figure 5. Alizarin red S (ARS) staining in the presence and absence of beta-aminopropionitrile (BAPN). (A) ARS staining was carried out every 3 days during osteoblast differentiation. Mouse calvaria cells were cultured in the presence of 0,1 or $2 \mathrm{mM} \mathrm{BAPN}$. A representative image is shown, and all 3 independent experiments produced similar results. (B) For quantitative assays, the bound ARS was dissolved in a 10\% cetylpyridinium chloride monohydrate, and absorbance was measured at $545 \mathrm{~nm}$. The assays were performed in triplicate, and the average is shown with an error bar representing the standard deviation. 
oxidase activity required for the formation of collagen fibers in osteoblast differentiation.

Osteoblasts pass through phenotypically distinct steps as they differentiate, including the biosynthesis, organization and mineralization of the bone extracellular matrix (22). Collagen synthesis occurs maximally during the biosynthesis phase and then decreases during the later organization and mineralization phases $(23,24)$. In the present study, we found that COL1A2 expression reached maximal levels on day 9 of differentiation and then diminished in the later stages when mineralized nodules were well formed, as previously observed $(23,24)$. An earlier study, using northern blot analysis, reported that LOX expression markedly increased in the early phases during the osteoblast differentiation of MC3T3-El cells and was then maintained at high levels during the mineralization phase (21); however, in our quantitative assays using primary mouse calvaria cells, $L O X$ expression was highest on day 9 and then gradually diminished in the later mineralization phase. We suggest that this variance reflects the phenotypic differences between the established MC3T3-El cell line and the primary cultured mouse calvaria cells. Alternatively, the variance may stem from the differences in experimental conditions, such as the observation time points or culture conditions.

The human LOX precursor is synthesized as a $48-\mathrm{kDa}$ pro-protein, and following extensive intracellular and extracellular processing, procollagen $\mathrm{C}$-protease, which is also known as bone morphogenic protein 1 (BMP1), proteolytically cleaves the LOX precursor into an enzymatically active 32-kDa protein in the extracellular matrix (25-27). As previously demonstrated, BMP1 is an astacin metalloprotease that plays an important role in extracellular matrix remodeling and osteogenesis $(28,29)$. In another previous study, an isoform of BMP1, BMP1-3, was also reported to enhance bone repair in rats with long bone fractures (30). A homozygous causative mutation in BMP1 was reported in a consanguineous family affected by increased bone mineral density and multiple recurrent fractures (31). The mutation was located within the BMP1 signal peptide, leading to impaired post-translational modification of the BMP1 precursor protein. Using a zebrafish model, BMP1 was shown to play a crucial role in the formation of mature collagen fibers in bone (31). Taken together, these findings suggest that BMP1 regulates osteogenesis through the proteolytic activation of LOX into the active 32-kDa protein, which is critically required for cross-linking of collagen monomers into mature collagen fibers. Further studies on the regulatory role of LOX in osteoblastogenesis will therefore provide valuable information regarding the molecular mechanisms associated with aberrant bone matrix formation.

\section{Acknowledgements}

This study was supported by the National Research Foundation (NRF) of Korea, funded by the Ministry of Education (nos. NRF-2011-0030130 and NRF-2015R1D1A3A01016577).

\section{References}

1. Knott L and Bailey AJ: Collagen cross-links in mineralizing tissues: a review of their chemistry, function, and clinical relevance. Bone 22: 181-187, 1998.
2. Yang H, Han S, Kim H, Choi YM, Hwang KJ, Kwo HC, Kim SK and Cho DJ: Expression of integrins, cyclooxygenases and matrix metalloproteinases in three-dimensional human endometrial cell culture system. Exp Mol Med 34: 75-82, 2002.

3. Stegemann JP and Nerem RM: Altered response of vascular smooth muscle cells to exogenous biochemical stimulation in twoand three-dimensional culture. Exp Cell Res 283: 146-155, 2003.

4. Keely PJ, Fong AM, Zutter MM and Santoro SA: Alteration of collagen-dependent adhesion, motility, and morphogenesis by the expression of antisense alpha2 integrin mRNA in mammary cells. J Cell Sci 108: 595-607, 1995.

5. Bailey AJ, Wotton SF, Sims TJ and Thompson PW: Biochemical changes in the collagen of human osteoporotic bone matrix. Connect Tiss Res 29: 119-132, 1993.

6. Wojtowicz A, Dziedzic-Goclawska A, Kaminski A, Stachowicz W, Wojtowicz K, Marks SC Jr and Yamauchi M: Alteration of mineral crystallinity and collagen cross-linking of bones in osteopetrotic toothless $(\mathrm{tl} / \mathrm{tl})$ rats and their improvement after treatment with colony stimulating factor- 1 . Bone 20: 127-132, 1997.

7. Oxlund H, Mosekilde L and Ortoft G: Reduced concentration of collagen reducible cross links in human trabecular bone with respect to age and osteoporosis. Bone 19: 479-484, 1996.

8. Kagan HM and Trackman PC: Properties and function of lysyl oxidase. Am J Respir Cell Mol Biol 5: 206-210, 1991.

9. Kim Y, Boyd CD and Csiszar K: A new gene with sequence and structural similarity to the gene encoding human lysyl oxidase. J Biol Chem 270: 7176-7182, 1995.

10. Saito H, Papaconstantinou J, Sato H and Goldstein S: Regulation of a novel gene encoding a lysyl oxidase-related protein in cellular adhesion and senescence. J Biol Chem 272: 8157-8160, 1997.

11. Jourdan-Le SC, Tomsche A, Ujfalusi A, Jia L and Csiszar K: Central nervous system, uterus, heart, and leukocyte expression of the LOXL3 gene, encoding a novel lysyl oxidase-like protein. Genomics 74: 211-218, 2001.

12. Asuncion L, Fogelgren B, Fong KS, Fong SF, Kim Y and Csiszar K: A novel human lysyl oxidase-like gene (LOXL4) on chromosome 10q24 has an altered scavenger receptor cysteine rich domain. Matrix Biol 20: 487-491, 2004.

13. Jung ST, Kim MS, Seo JY, Kim HC and Kim Y: Purification of enzymatically active human lysyl oxidase (LOX) and lysyl oxidase-like protein (LOXL) from Escherichia coli inclusion bodies. Protein Expr Purif 31: 240-246, 2003.

14. Kim MS, Kim SS, Jung ST, Park JY, Yoo HW, Ko J, Csiszar K, Choi S and Kim Y: Expression and purification of enzymatically active forms of the human lysyl oxidase-like protein 4. J Biol Chem 278: 52071-52074, 2003.

15. Lee JE and Kim Y: Tissue-specific variant of the human lysyl oxidase-like protein 3 (LOXL3) functions as an amine oxidase with substrate specificity. J Biol Chem 281: 37282-37290, 2006.

16. Kim YM, Kim EC and Kim Y: The human lysyl oxidase-like 2 protein functions as an amine oxidase toward collagen and elastin. Mol Biol Rep 38: 145-149, 2011.

17. Livak KJ and Schmittgen TD: Analysis of relative gene expression data using real-time quantitative PCR and the 2(-Delta Delta C(T)) method. Methods 25: 402-408, 2001.

18. Palamakumbura AH and Trackman PC: A fluorometric assay for detection of lysyl oxidase enzyme activity in biological samples. Anal Biochem 300: 245-251, 2002.

19. Owen TA, Aronow M, Shalhoub V, Barone LM, Wilming L, Tassinari MS, Kennedy MB, Pockwinse S, Lian JB and Stein GS: Progressive development of the rat osteoblast phenotype in vitro: reciprocal relationships in expression of genes associated with osteoblast proliferation and differentiation during formation of the bone extracellular matrix. J Cell Physiol 143: 420-430, 1990.

20. Atsawasuwan P, Mochida Y, Parisuthiman D and Yamauchi M: Expression of lysyl oxidase isoforms in MC3T3-E1 osteoblastic cells. Biochem Biophys Res Commun 327: 1042-1046, 2005.

21. Hong HH, Pischon N, Santana RB, Palamakumbura AH, Chase HB, Gantz D, Guo Y, Uzel MI, Ma D and Trackman PC: A role for lysyl oxidase regulation in the control of normal collagen deposition in differentiating osteoblast cultures. J Cell Physiol 200: 53-62, 2004.

22. Stein GS, Lian JB, Stein JL, Van Wijnen J and Montecino M: Transcriptional control of osteoblast growth and differentiation. Physiol Rev 76: 593-629, 1996.

23. Franceschi RT and Iyer BS: Relationship between collagen synthesis and expression of the osteoblast phenotype in MC3T3-E1 cells. J Bone Miner Res 7: 235-246, 1992. 
24. Quarles LD, Yohay DA, Lever LW, Caton R and Wenstrup RJ: Distinct proliferative and differentiated stages of murine MC3T3-E1 cells in culture: an in vitro model of osteoblast development. J Bone Miner Res 7: 683-692, 1992.

25. Cronshaw AD, Fothergill-Gilmore LA and Hulmes DJ: The proteolytic processing site of the precursor of lysyl oxidase. Biochem J 306: 279-284, 1995.

26. Uzel MI, Scott IC, Babakhanlou-Chase H, Palamakumbura AH, Pappano WN, Hong HH, Greenspan DS and Trackman PC: Multiple bone morphogenetic protein 1-related mammalian metalloproteinases process pro-lysyl oxidase at the correct physiological site and control lysyl oxidase activation in mouse embryo fibroblast cultures. J Biol Chem 276: 22537-22543, 2001.

27. Atsawasuwan P, Mochida Y, Katafuchi M, Tokutomi K, Mocanu V, Parker CE and Yamauchi M: A novel proteolytic processing of prolysyl oxidase. Connect Tissue Res 52: 479-486, 2011.
28. Bond JS and Beynon RJ: The astacin family of metalloendopeptidases. Protein Sci 4: 1247-1261, 1995.

29. Sterchi EE, Stocker W and Bond JS: Meprins, membrane-bound and secreted astacin metalloproteinases. Mol Aspects Med 29: 309-328, 2008.

30. Grgurevic L, Macek B, Mercep M, Jelic M, Smoljanovic T, Erjavec I, Dumic-Cule I, Prgomet S, Durdevic D, Vnuk D, et al: Bone morphogenetic protein (BMP)1-3 enhances bone repair. Biochem Biophys Res Commun 408: 25-31, 2011.

31. Asharani PV1, Keupp K, Semler O, Wang W, Li Y, Thiele H, Yigit G, Pohl E, Becker J, Frommolt P, et al: Attenuated BMP1 function compromises osteogenesis, leading to bone fragility in humans and zebrafish. Am J Hum Genet 90: 661-674, 2012. 